\title{
Prémio Europeu da Química Sustentável 2021 Atribuído a James Clark
}

O Prémio Europeu de Química Sustentável, atualmente concedido pela Divisão da Química Verde e Sustentável a cientistas de excelência nesta vertente, tem como principal objetivo impulsionar esta área da Química. Pretende-se dar uma maior visibilidade ao esforço de cientistas europeus para a implementação da Química Verde no campo industrial e ser um motor para melhorar a inovação g'lobal e competitividade. Este prémio é bienal e anteriormente era proposto pela Divisão da Química Verde e Sustentável (Division of Green and Sustainable Chemistry) em conjunto com a Divisão da Química e

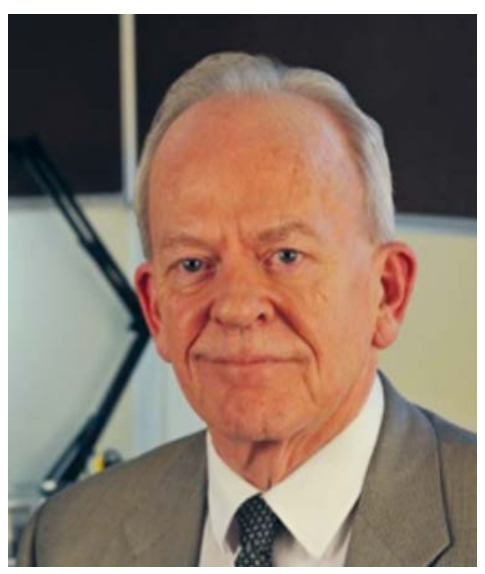

Ambiente (Division of Chemistry and Environment) da Sociedade de Química Europeia (European Chemical Society, EuChemS). A partir do presente ano é proposto apenas pela Divisão da Química Verde e Sustentável.

Em 2021, será o Professor James Clark, do Centro de Excelência de Química Verde da Universidade de York, Reino Unido, o cientista agraciado com o Prémio Europeu da Química Sustentável 2021 (ESCA 2021). Este prémio reconhece a excelência do contributo prestado por James Clark para a comercialização da investigaação fundamental em química verde, o seu notável papel para o reconhecimento desta área como uma área distinta da química e ainda para a criação de uma comunidade científica global de química verde.

O vencedor do prémio ESCA 2021 será orador na 5. ${ }^{a}$ conferência da Divisão de Química Verde e Sustentável da EuChemS (5EUGSC), que este ano decorrerá de 26 a 29 de setembro, como conferência virtual devido à atual situação pandémica que se vive a nível mundial (5eugssc.org).

A Presidente da Divisão, Ana Aguiar-Ricardo, agradece a valiosa contribuição dos membros do Júri do Prémio ESCA.

Ana Aguiar-Ricardo p19@fct.unl.pt

\section{Timothy Noël Vence o Prémio IUPAC-ThalesNano 2020 para Química de Fluxo}

O prémio IUPAC-ThalesNano 2020 para Química de Fluxo foi concedido ao Professor Timothy Noël do Instituto Van't Hoff de Ciências Moleculares da Universidade de Amsterdão. 0 prémio homenageia contribuições notáveis no campo da química de fluxo, microfluídica, microfabricação e engenharia de microssistemas.

Este prémio, estabelecido pela empresa de tecnologia

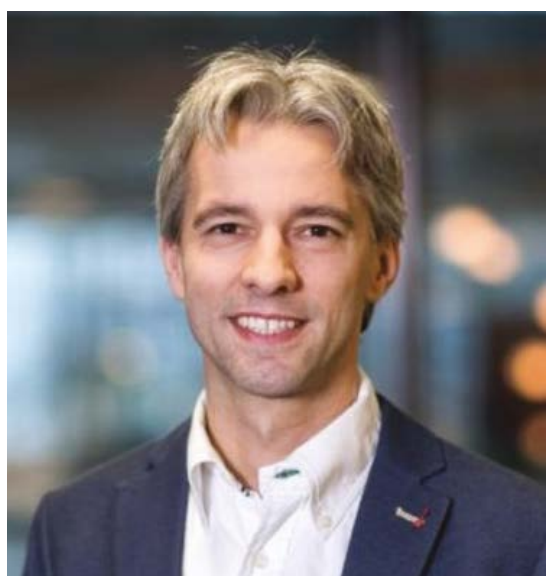


húngara ThalesNano e concedido por um júri internacional sob os auspícios da IUPAC, visa reconhecer o papel fundamental que a Química de Fluxo desempenha na melhoria dos processos químicos.

O professor Timothy Noël é um dos líderes no campo da Química de Fluxo e, na última década, produziu contribuições científicas criativas na interface entre a Química e a Engenharia Química, sendo pioneiro em novas estratégias e tecnologias catalíticas de fluxo contínuo em síntese orgânica. Estas ferramentas encontraram uma implementação signnificativa na indústria farmacêutica, superando vários desafios sintéticos.

0 prémio deveria ser entregue durante o Congresso de Química de Fluxo 2021 agendado para abril em Boston (EUA), mas foi recentemente adiado devido à pandemia de COVID-19.

\section{$>$}

Bruno Machado

brunofm@fe.up.pt

\section{Mulheres Distintas em Química ou Engenharia Química IUPAC 2021}
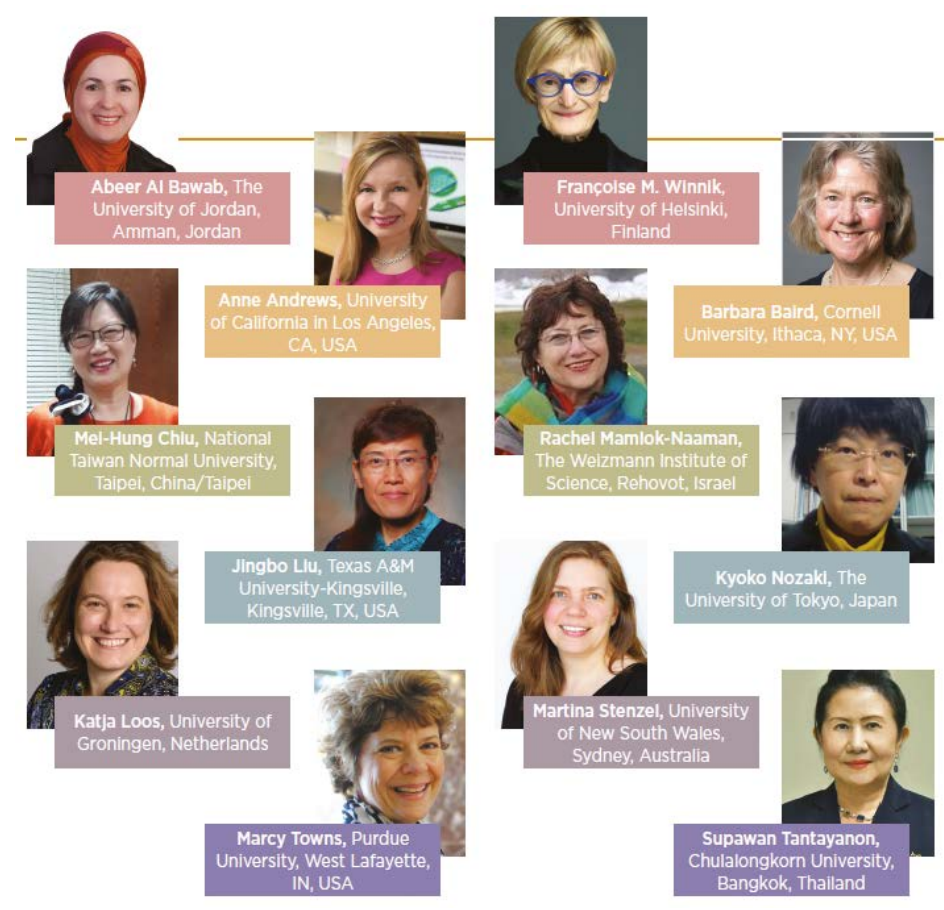

No dia 11 de fevereiro de 2021, por ocasião do Dia Internacional das Mulheres e Raparigas na Ciência, a IUPAC anunciou a lista de 12 vencedoras do "Mulheres Distintas em Química ou Engenharia Química IUPAC 2021" (IUPAC 2021 Distinguished Women in Chemistry or Chemical Engineering). Iniciada em 2011 por ocasião do Ano Internacional da Química, esta distinção tem decorrido em cada Assembleia Geral bienal da IUPAC e Congresso Mundial de Química.

O seu objetivo é reconhecer e promover o trabalho de mulheres Químicas ou Engenheiras Químicas em todo o mundo. Os prémios serão entregues às 12 vencedoras durante o Congresso Mundial de Química da IUPAC, que se realizará em agosto de 2021.

A seleção das 12 premiadas teve como base a excelência em investigação básica ou aplicada, realizações notáveis no ensino ou educação, ou demonstração de liderança ou excelência nas ciências químicas.

A lista contendo todas as vencedoras deste prémio desde 2011 pode ser consultada em iupac.org/wp-content/uploads/2021/02/Recipients-IUPAC-Distinguished-Women-in-Chemistry-or-Chemical-Engineering_20210208.pdf.

Bruno Machado

brunofm@fe.up.pt

\section{Mulheres na Ciência 2021}

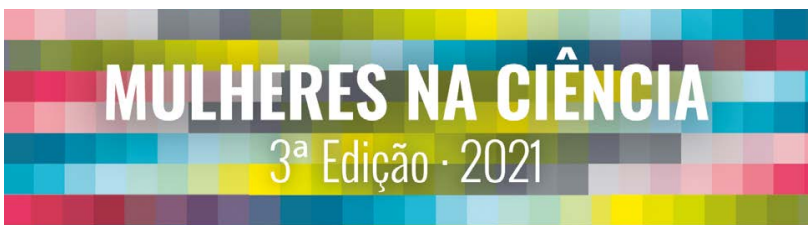

Mulheres na Ciência, 3. ${ }^{\text {a }}$ edição, 2021. ISBN: 978-989-54649-5-1. Ciência Viva - Agência Nacional para a Cultura Científica e Tecnológica
O livro "Mulheres na Ciência"(3. a edição), uma iniciativa da Ciência Viva, foi lançado no passado dia 8 de março, Dia Internacional da Mulher. Com retratos de cientistas de diferentes gerações e áreas do conhecimento (Ambiente e Alterações Globais, Arquitetura, Bioengenharia e Biotecnologia, Ciência Política e Direito, Ciências Agrárias e Florestais, Ciências Biológicas, Ciências da Educação, Ciências da Saúde, Ciências da Terra, Ciências Sociais e Humanas, Economia e Gestão, Engenharias, Filosofia, Física, História, Matemática, Química e Bioquímica), 